\title{
AUMENTO NA PRODUTIVIDADE DA CANA-DE-AÇÚCAR ATRAVÉS DA IRRIGAÇÃO
}

\author{
FREITAS, Ricardo Galvão de ${ }^{1}$ \\ BAFFA, David Carlos Ferreira ${ }^{1}$ \\ BRASIL, René Porfirio Camponez do ${ }^{2}$
}

Recebido em: 2008-06-10

Aprovado em: 2009-06-25

ISSUE DOI: $10.3738 / 1982.2278 .91$

RESUMO: A necessidade de busca da otimização dos recursos produtivos, o aumento da competitividade no mercado produtivo, a necessidade de aumento de produtividade e a redução de custos levam a uma tendência de adoção de tecnologias capazes de tornar a exploração agrícola cada vez mais competitiva e rentável. A irrigação exerce papel fundamental no agronegócio, como uns dos principais instrumentos para modernização da agricultura brasileira, permitindo enormes benefícios, em especial no caso do cultivo da cana-de-açúcar. A irrigação é uma prática ainda em estudo para a cultura da cana-deaçúcar, no entanto, quando aliada às condições climáticas como temperatura e luminosidade, pode aumentar a produtividade e melhorar a qualidade, garantindo bons rendimentos ao produtor.

Palavra Chave: Irrigação. Água. Produtividade.

SUMMARY: The need of searching for optimization of productive resources, the increase of competitiveness in the production market, the need of increasing productivity and reduce lead to a trend of deploying technologies capable of making the farm increasingly competitive and profitable. The irrigation has a fundamental place in agribusiness, as one of the main instruments for Brazilian agriculturemodernization, allowing great benefits, specially in the cultivation of sugarcane. The irrigation is a practice that is still under study for sugarcane cultivation, however, when coupled with climatic conditions such as temperature and luminosity, may increase the productivity and improve quality, ensuring good returns to the producers.

Keywords: Irrigation. Sugar cane. Water. Productivity.

\section{INTRODUÇÃO}

Historicamente, a cana de açúcar é um dos principais produtos agrícolas do Brasil, sendo cultivada desde a época da colonização. A cultura da cana-de-açúcar tem um grande destaque sócio-econômico em nosso país. A indústria canavieira, com

\footnotetext{
1 Engenheiro Agrônomo, Universidade Federal de Viçosa-UFV. Pós-Graduação em Gestão e Tecnologia Sucroalcooleira, Faculdade de Agronomia Doutor Francisco Maeda-FAFRAM. E-mail: ricardogalvaoagro@yahoo.com.br; davidbaffa@yahoo.com.br

2 Engenheiro Agrônomo, Professor, Faculdade Doutor Francisco Maeda-FAFRAM . E-mail: rpcbrasil@hotmail.com
} 
aproximadamente 350 indústrias de açúcar e álcool, ocupa cerca de 5.677.396 hectares de área, gerando 1.000 .000 de empregos diretos e indiretos, e possui uma capacidade de produção de 396.012.158 toneladas de cana-de-açúcar, na safra de 2003/2004, sendo $55 \%$ destinadas à produção de álcool anidro e hidratado e 45\%, de açúcar (IBGE, 2004).

Outros produtos, também originados dessa cultura e que devem ser salientados, são o a aguardente (muito consumido), o bagaço (que é utilizado principalmente como fonte de energia), a vinhaça (que serve de fertilizante), o plástico e o papel (SOUZA et al, 1999). A cana é, em si, usina de enorme eficiência, uma vez que cada tonelada tem um potencial energético equivalente ao de 1,2 barril de petróleo. O Brasil é o maior produtor do mundo, seguido da Índia e Austrália. Na média, 55\% da cana brasileira se transformam em álcool e $45 \%$ em açúcar. No país, planta-se cana no Centro-Sul e no Norte-Nordeste, o que permite dois períodos de safra (UNICA, 2004).

De acordo com Bernardo (2005), a irrigação no Brasil, infelizmente, ainda não está sendo praticada com eficiência, portanto, ao manejar de forma racional qualquer projeto de irrigação, devem-se considerar os aspectos sociais e ecológicos da região e procurar maximizar a produtividade e a eficiência de uso de água e minimizar os custos, quer de mão- de- obra, quer de capital, de forma a tornar lucrativa a utilização da irrigação. Ou seja, não se deve fazer irrigação só para dizer que se está fazendo agricultura irrigada, mas sim com o objetivo de aumentar o lucro, com o aumento da produtividade, quer em quantidade, quer em qualidade.

Um bom programa de irrigação pode beneficiar a cultura de muitos modos, a saber: aumentando sua produtividade, permitindo maior eficiência no uso de fertilizantes, permitindo uma programação de cultivo, isto é, a elaboração de uma escala de plantio que possibilite a obtenção de duas ou mais colheitas por área/ano, permitindo a introdução de cultivos mais caros, minimizando o risco de investimentos na agricultura, etc. Mas é de capital importância que se tenha consciência de que a irrigação, como prática isolada, não propiciará os benefícios desejados, pois precisa ser acompanhada de outras práticas culturais para poder gerar os lucros esperados da exploração agrícola irrigada, tais como: variedades produtivas, adubação e tratos culturais apropriados.

Ainda segundo Bernardo (2005), a finalidade básica da irrigação é proporcionar água às culturas de maneira a atender as exigências hídricas durante todo seu ciclo, possibilitando altas produtividades e produtos de boa qualidade. A quantidade de água necessária às culturas é função da espécie cultivada, do local de cultivo, do estágio de 
desenvolvimento da cultura, do tipo de solo e da época de plantio. Portanto, este artigo fala sobre a irrigação na cultura da cana-de-açúcar e seus principais benefícios à cultura.

\section{REVISÃO DE LITERATURA}

\subsection{Importância da irrigação para a cultura da cana}

A utilização da irrigação na cultura da cana tem sido uma importante estratégia em função dos seguintes benefícios: aumento da produtividade (normalmente superior a 140 T/ha), ampliação da longevidade do plantio (acima de 10 safras), redução da área plantada (redução nos custos do plantio e de manutenção), diminuição da infra-estrutura (estradas e outras infra-estruturas, equipe técnica e de campo), estabilização da produtividade (diminui a variabilidade da produção de um ano a outro), custo menor de colheita e transporte (menores áreas, talhões mais produtivos, menores distâncias), utilização racional do vinhoto (distribuição pode ser feita utilizando-se o próprio sistema de irrigação, o que reduz custos e permite um planejamento mais racional do uso da mesma).

Há três concepções distintas de irrigação na cultura da cana:

a) Irrigação de salvamento: Consiste em aplicar lâmina de 40 a $80 \mathrm{~mm}$ após cada corte anual, com intuito de "salvar" a soca. Este tipo de irrigação, em algumas regiões do cerrado, é de fundamental importância para a viabilidade econômica da cana-de-açúcar. b) Irrigação com déficit: Consiste em aplicar lâminas acumuladas de 200 a 300 mm/ano. Neste caso, faz-se necessário realizar estudo climático da região, para, baseado no balanço-hídrico, definir estratégia de decisão de irrigação. Para implantar esta estratégia de produção, é fundamental realizar estudo prévio da viabilidade de projetos de irrigação, tipo de sistemas, autonomia de lâmina diária, custo da energia elétrica, elevação de produtividade e longevidade esperada.

c) Irrigação plena ou total: Consiste em aplicar lâminas acumuladas de 450 a 700 mm/ano. Neste caso, é fundamental que haja disponibilidade de água e realização de estudo climático da região, para, baseando-se no balanço-hídrico, definir estratégia de decisão de irrigação. Para implantar esta estratégia de produção, é fundamental realizar estudo prévio da viabilidade dos projetos de irrigação, tipo de sistemas, autonomia de lâmina diária, custo da energia elétrica, elevação de produtividade e longevidade esperada. 
Apesar da cultura da cana ser amplamente cultivada sem irrigação ou com irrigação de salvamento, diversos aspectos relacionados a perspectivas de um mercado em forte expansão, associado aos grandes avanços na área da irrigação (mais competitivo), fazem com que haja grande perspectiva de ampliação da área irrigada com cana-de-açúcar no Brasil e em outras partes do mundo. A tecnologia da irrigação vem sendo introduzida como alternativa de melhoria na qualidade do processo de produção sucro-alcooleiro. Pesquisas atuais com cana irrigada têm mostrado altos índices de produtividade e eficiência econômica, sendo observados grandes variações nos resultados, indicando a importância da análise das condições locais de clima, solo, topografia e manejo da cultura e da irrigação. A condução da cultura da cana irrigada é uma possibilidade real para ampliar a rentabilidade e operacionalidade do processo de produção e deve ser analisado caso a caso.

Especialmente para a cana, ensaios experimentais, realizados em diversas regiões do Brasil, têm demonstrado que reduções da Evapotranspiração potencial da cultura entre 25 e $50 \%$ têm mantido ainda o máximo potencial produtivo. Em outras palavras, não há necessidade de fornecer todo o requerimento hídrico para a cana, podendo-se aproveitar a capacidade da cultura em restringir a capacidade de absorver água, manejando racionalmente o nível de déficit hídrico e, ainda, promovendo alta eficiência produtiva.

Dessa maneira, a implantação de projetos de irrigação de cana com concepção de irrigação com déficit, utiliza sistemas do tipo linear ou pivôs rebocáveis, com menor autonomia de lâmina diária, objetivando racionalizar o uso de água, custo geral dos projetos e maximizar o retorno econômico da cana irrigada.

A irrigação com déficit é fundamentada na implantação do gerenciamento de irrigação com definição da estratégia de irrigação de acordo com o clima, fase da cultura, solo e equipamento de irrigação. Como haverá restrição da quantidade de irrigação a ser realizada, cada lâmina deverá ser aproveitada o máximo possível.

Neste caso, monitora-se o comportamento da umidade do solo diariamente, para que a mesma não seja menor que a umidade de segurança definida a partir de estudos físico-hídricos. As irrigações ficam registradas, compondo o balanço hídrico diário e o histórico das irrigações realizadas por talhão.

Segundo Doorenbos Kassan (1979), o manejo correto da irrigação não permite a ocorrência de déficits prejudiciais à rentabilidade econômica da cultura e deve ser feito de acordo com as tensões de água no solo, recomendadas para cada período do ciclo 
fenológico, obedecendo às seguintes recomendações: durante o período de nascimento, estabelecimento das plântulas e início do período vegetativo, a cultura demanda pequenas lâminas que devem ser aplicadas em turnos de rega pequenos; durante a segunda fase do período vegetativo (alongamento do colmo) e primeira fase da formação da parte colhível, a cultura, devido ao crescimento do sistema radicular, passa a dispor de maior volume de água disponível no solo, devendo-se aplicar lâminas maiores em turnos de rega também maiores do que os períodos anteriores; na segunda fase do período de formação da colheita, a exigência da planta diminui, devendo-se aplicar lâminas menores que as da fase anterior; e, durante o período de maturação, as lâminas devem ser ainda menores, para aumentar a concentração de sacarose e a irrigação suspensa nos últimos dias que antecedem a colheita.

$\mathrm{Na}$ agricultura irrigada, o fator água deve ser otimizado, possibilitando, sem maiores riscos, aumentar a utilização dos demais fatores de produção e, por conseqüência, obter maiores produtividades com uma melhor combinação dos insumos empregados. Para tanto, as determinações dos efeitos da lâmina total aplicada (precipitação + irrigação) na produtividade da cana-de-açúcar, explicitados em tabelas, funções de produção ou superfícies de resposta são fundamentais para auxiliar nas decisões, haja vista que estas tabelas ou funções possibilitam determinar as interações entre os diversos fatores que afetam a produtividade e escolher as soluções mais condizentes com a realidade regional, permitindo, assim, o manejo racional da irrigação em bases técnicas e econômicas (BERNARDO, 2006).

O uso da irrigação na cana-de-açúcar será tanto mais benéfico/necessário quanto maior for a extensão do déficit hídrico (número de meses do ano) e se fará vantajoso quanto mais arenoso for o solo onde a cana estiver plantada. Solos arenosos têm menos capacidade de armazenamento de água (retenção de água das chuvas) e, muitas vezes, uma chuva intensa no início do mês pode não garantir o fornecimento de água às plantas no final do mês. Também o uso da irrigação em cana pode representar um melhor pegamento da cana recém-plantada, podendo ser sinônimo de maior produtividade, de antecipação da colheita, especialmente nas variedades mais precoces. Ainda uma grande vantagem é o aumento da expectativa da vida útil de um canavial, passando de 5 para 8 - 10 anos para se iniciar a reforma e um novo plantio. 


\subsection{Irrigação na cana-de-açúcar}

Para quantificar os benefícios econômicos da irrigação, é necessário saber quantificar o esperado aumento na produtividade em função do aumento de água aplicada. A representação gráfica ou matemática desta relação é denominada função de produção água-cultura.

Estudos agro-econômicos utilizando função de produção, são bastante difundidos em alguns países. A utilização destas funções para determinar os níveis ótimos e econômicos dos fatores de produção é o que tem permitido melhorar o desempenho daqueles produtores. No Brasil, ainda são poucos os trabalhos realizados nesta linha de pesquisa e concentram-se, em sua maioria, na determinação das dosagens mais econômicas de fertilizantes.

Uma função de produção "água-cultura" típica é quando relacionamos "lâmina de água aplicada durante o ciclo da cultura" versus "produtividade comercial". Outra maneira de expressar funções de produção "água-cultura" é relacionar lâminas aplicadas por estágios de desenvolvimentos da cultura ou evapotranspiração ou tensão ou umidade do solo versus produtividade.

Na Figura 1, tem-se um exemplo clássico de uma função de produção "águacultura" (BERNARDO,1996).

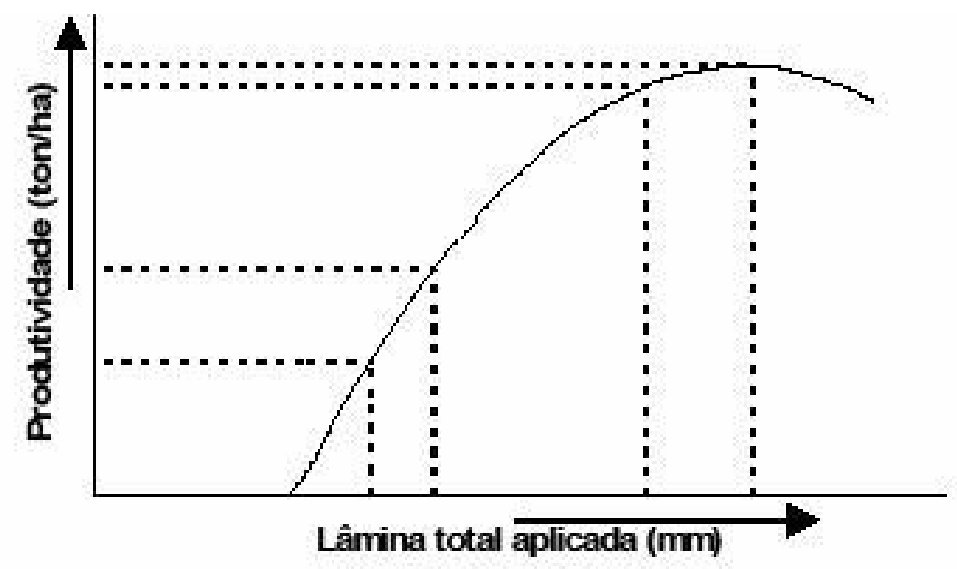

FIGURA 1: Exemplo Típico de Função de Produção “Água - Cultura”.

Em função da demanda, novas regiões estão sendo, rapidamente, incorporadas às regiões produtoras tradicionais. No entanto, para que o crescimento do setor seja mantido em condições rentáveis, ele deverá ser apoiado não apenas na ampliação das áreas agrícolas, mas também no aumento da produtividade, especialmente considerando, 
da parte do produtor agrícola, a redução do seu retorno financeiro verificada nos últimos dois anos. Deste modo, é de capital importância a aplicação de novas técnicas que visem à otimização do setor, no que diz respeito à evolução tecnológica, de forma a proporcionar contínua elevação dos índices de produtividade por área, uma vez que a cultura possui um potencial biológico de 345,6 toneladas por hectare/ano, a depender de fatores como clima, solo e manejo fitotécnico.

A exigência de água pela cultura varia em função do ciclo da cultura (cana planta, soca ou ressoca), do estágio de desenvolvimento da cultura (ciclo fenológico), das condições climáticas e de outros fatores, como água disponível no solo e variedades utilizadas e, de acordo com alguns estudiosos do assunto, o consumo anual de água pela cultura fica em torno de 1.500 a $2.500 \mathrm{~mm}$, sendo, porém, muito difícil estabelecer uma relação geral entre produção e consumo de água pela cana-de-açúcar, devido às variações de localização, clima, variedades e solo.

Segundo Santos (2005), no cultivo irrigado da cana-de-açúcar é de capital importância definir os estágios de desenvolvimento da cultura a fim de otimizar a eficiência de aplicação da irrigação. Assim sendo, pode - se dividir o ciclo da cana de doze meses em quatro (04) estágios de desenvolvimento:

- Germinação e emergência = 1 mês;

- Perfilhamento e estabelecimento da cultura = 2 a 3 meses;

- Desenvolvimento da cultura $=6$ a 7 meses;

- Maturação = 2 meses.

Os dois primeiros estágios são os mais críticos ao déficit hídrico. O terceiro estágio (desenvolvimento) responde à lâmina aplicada, mas o déficit hídrico não causa tantos prejuízos à produtividade quanto os dois primeiros. O quarto estágio (maturação) responde positivamente ao déficit hídrico. Entretanto o consumo diário de água é maior no terceiro estágio do que nos dois primeiros; ocorrendo isso em função do maior índice de área foliar no terceiro estágio. O teor de açúcar costuma ser afetado adversamente pelo excesso de umidade no estagio de maturação. Os valores de Kc para a cana- deaçúcar de acordo com Doorenbos e Kassam (1994), citados por Santos (2005), podem ser assim definidos nas Tabelas 1 e 2 . 
TABELA 1: Valores de Kc para cana-planta.

\begin{tabular}{l|l|l}
\hline \multicolumn{1}{c|}{ PERIODO } & DIAS DO CICLO & \multicolumn{1}{c}{$\begin{array}{c}\text { COEFICIENTE DE } \\
\text { CULTURA (Ke) }\end{array}$} \\
\hline Do plantio até25\% de cobertura & 30 a 60 dias & 0,40 a 0,60 \\
De 25\% a 50\% de cobertura & 30 a 40 dias & 0,75 a 0,85 \\
De 50\% a 75\% de cobertura & 15 a 25 dias & 0,9 a 1,00 \\
De 75\% a cobertura completa & 45 a 55 dias & 1,00 a 1,20 \\
Utilização máxima & 180 a 330 dias & 1,05 a 1,30 \\
Início da senescência & 30 a 150 dias & 0,80 a 1,05 \\
Maturação & 30 a 60 dias & 0,60 a 0,75 \\
\hline Fonte: Doorenbose Kassam(1994)
\end{tabular}

TABELA 2: Valores de Kc para cana-soca.

\begin{tabular}{l|l|l}
\hline \multicolumn{1}{c|}{ PERIODO } & \multicolumn{1}{c|}{ DIAS DO CICLO } & \multicolumn{1}{c}{$\begin{array}{c}\text { COEFICIENTE DE } \\
\text { CULTURA (Kc) }\end{array}$} \\
\hline Do plantio até25\% de cobertura & 0 a 1 mês & 0,55 \\
De 25\% a 50\% de cobertura & 1 a 2 meses & 0,80 \\
De 50\% a 75\% de cobertura & 2 a 2,5 meses & 0,90 \\
De 75\% a cobertura completa & 2,5 a 4 meses & 1,00 \\
Cobertura total do solo & 4 a 10 meses & 1,05 \\
Início da maturação & 10 a 11 meses & 0,80 \\
Maturação & 11 a 12 meses & 0,60 \\
\hline
\end{tabular}

Fonte: Doorenbose Kassam(1994)

\subsection{Aumento na produtividade da cana-de-açúcar}

Além da relevância do cultivo irrigado de cana-de-açúcar no aumento da produtividade, da produção e do número de cortes por plantio (vida útil do canavial) e, como conseqüências, no aumento do lucro do produtor, existem os benefícios socioeconômicos indiretos, tais como o aumento do número de empregos na região, os quais somente serão duradouros se os cultivos irrigados tiverem sustentabilidade econômica, social e ambiental.

Trabalhos de pesquisa em várias regiões do país com algumas variedades de cana-de-açúcar têm demonstrado o efeito da irrigação no aumento da produtividade, tanto de colmo como de açúcar. Alguns dos quais passamos a apresentar de forma resumida.

Trabalho conduzido na região Norte Fluminense - RJ por Elias Fernandes de Sousa e Salassier Bernardo evidencia a importância da irrigação na produtividade da cana-de-açúcar. O experimento foi realizado em área da Fazenda Boa Vista, pertencente 
à Usina Santa Cruz, em Campos dos Goytacazes, RJ. Foi iniciado com o plantio da cana- de- açúcar, no dia 27/07 / 1995 e finalizado com a colheita no dia 19/10/1996. O experimento recebeu uma aplicação de maturador (Glyfosato) em 30/08 /1996 (13 meses de cultivo). A queima para colheita foi realizada em 15/10 /1996 e o corte no período de 16 a 18/10 /1996.

Durante o experimento, as precipitações pluviais totalizaram $937 \mathrm{~mm}$. Para o completo estabelecimento da cultura, realizaram-se três irrigações no período de agosto a novembro de 1995. O total de água aplicada, neste período, computada pela lâmina média, aplicada pelo sistema de irrigação, foi de $126 \mathrm{~mm}$. No período subseqüente, até a colheita, foram realizadas 12 irrigações, utilizando - se o sistema Point Source.

À medida que se aumentou a quantidade de água aplicada (irrigação + precipitação), houve incrementos positivos de produtividade até atingir um valor máximo. Após esse valor, houve decréscimo de rendimento com o aumento de lâmina total aplicada.

Isso pode ser explicado pelo fato de a água ser um fator limitante à produção. À medida que se aumenta sua disponibilidade, a cultura pode expressar melhor o seu potencial produtivo até um determinado ponto, após o qual a produtividade passa a decrescer, devido ao excesso de água no solo, à baixa aeração na zona radicular e a lixiviação de nutrientes. Verifica-se que o incremento máximo de produtividade, devido à irrigação, foi 84 e 75 ton/ha para as variedades RB72454 e SP701011, respectivamente. Quando se utilizou a função de produção, os incrementos máximos de produtividade foram estimados em 68 e 52 ton/ha para as duas variedades. A variedade RB72454 apresentou a maior produtividade de colmos.

O rendimento e a produção de açúcar e de álcool da cana-de-açúcar irrigada dependem da quantidade de água aplicada, do manejo de irrigação combinado com a quantidade certa de adubação, da variedade, da idade do corte, do tipo de solo e do clima. Souza et al. (1999), utilizando sistema de irrigação por aspersão tipo canhão, encontraram, para as variedades RB72-454, RB76-418 e SP70-1011, máximas produtividades em colmos de 155,8, 126,9 e 141,9 ton/ha, com lâminas totais de água de 1568, 1424 e 1589 mm, respectivamente, em 13 meses de cultivo. As máximas produtividades em açúcar, estimadas para as mesmas variedades, foram 20,7; 17,1 e 19,3 ton/ha, para as lâminas de 1678, 1874 e 1602 mm, respectivamente, nos mesmos 13 meses de cultivo. Gomes (1999) obteve, com cana-planta, variedade RB72-454, e uma lâmina média de $1195 \mathrm{~mm}$, uma produtividade média de colmos e em açúcar de 
130 e 17 ton/ha, respectivamente. Maule et al. (2001) encontraram, no Estado de São Paulo, para a variedade SP79-1011, produtividades médias de 149, 154 e 170 ton/ha, respectivamente, para precipitações totais de $1.478 \mathrm{~mm}$ com 14 meses de cultivo, 1.695 mm com 17 meses de cultivo e 1.829 mm com 19 meses de cultivo; já Azevedo (2002) encontrou, para a mesma variedade, nos tabuleiros costeiros da Paraíba, produtividades de 52, 79, 93 e 92 ton/ha para precipitação efetiva mais irrigação de 609, 761, 905 e $1043 \mathrm{~mm}$, respectivamente, com doze meses de cultivo.

Nos trópicos, a produtividade da cana- de- açúcar, na faixa de 70 a 120 t/há, pode ser considerada bom rendimento no cultivo de sequeiro. Mas, na maioria das nossas regiões, a produtividade da cana, sob o cultivo de sequeiro, está bem abaixo desses valores e, no cultivo irrigado, é comum não ultrapassar 100 t/ha.

Segundo Veiga et al. (2006), a produtividade da cana-de-açúcar, no Brasil, no período de 1970 a 2004, aumentou de forma significativa, variando de 46,23 t/há, na safra 1970/71, a 73,88 t/ha, na safra 2004/05. No estado do Rio de Janeiro, a produtividade, no período de 1990 a 2004, aumentou 10 t/há, variando de 44,88 t/ha na safra 1990/91 a 54,88 t/há na safra 2004/05.

O consumo diário de água pela cana- de-açúcar nas principais regiões produtoras do país, dependendo da variedade, do estágio de desenvolvimento da cultura, da demanda evapotranspirométrica em função do mês e da região (variação temporal e espacial), em geral, tem variado de 2,0 a $6,0 \mathrm{~mm} /$ dia.

Na usina Cururipe, situada na região litoral Sul de Alagoas, na safra 2003/2004, obtiveram, em 27.712 hectares, produtividade média de 91,40 ton/há; sendo que, para a variedade SP79-1011, as médias da soca e ressoca, sob 2 ou 3 irrigações de $60 \mathrm{~mm}$ por irrigação e não irrigadas, foram 111,3 e 89,2 ton/ha respectivamente (Santos, 2005).

Guazzelli e Paes, citado por Santos (2005), estudando a produtividade da variedade SP80-1842, ciclo cana planta, na usina São Martinho, Ribeirão Preto-SP, obtiveram os seguintes dados mostrados na tabela 3 . 
TABELA 3: Produção de cana-planta irrigada e não irrigada (variedade SP80 - 1842).

\begin{tabular}{|c|c|c|c|c|}
\hline \multicolumn{2}{|c|}{ Tratamento } & \multirow{2}{*}{$\begin{array}{c}\text { Produtividad } \\
\mathrm{e} \\
(\mathrm{t} / \mathrm{ha})\end{array}$} & \multicolumn{2}{|c|}{ Aumento de Produtividade } \\
\hline Irrigação & Lâmina (mm) & & $(\mathrm{t} / \mathrm{ha})$ & $(\%)$ \\
\hline $100 \%$ da $\mathrm{ETr}$ & 946 & 173 & 29 & 20,1 \\
\hline $75 \%$ da $\mathrm{ETr}$ & 710 & 169 & 25 & 17,4 \\
\hline $50 \%$ da ETr & 473 & 174 & 30 & 20,8 \\
\hline $25 \%$ da ETr & 237 & 166 & 22 & 15,3 \\
\hline Testemunha & 0 & 144 &. & .. \\
\hline
\end{tabular}

ETr - Evapotranspiração real da cultura

Demétrio, também citado por Santos (2005) em trabalho com irrigação suplementar, na variedade NA5679, em Piracicaba-SP, obteve produtividade de 140,0 com irrigação e 107,4 ton/ha sem irrigação.

A tabela 4 nos mostra um dos ensaios realizados pelo antigo Planalsucar na região de Campos - RJ, com os seguintes resultados:

TABELA 4: Ensaio Irrigação por Aspersão 03 x $30 \mathrm{~mm}$, verificando a produtividade (ton/ha) de três diferentes variedades em Campos - RJ .

\begin{tabular}{|lccccccr|}
\hline & \multicolumn{3}{c}{ IRRIGADO } & \multicolumn{3}{c|}{ SEQUEIRO } \\
\hline & & CB 45-3 & NA 5679 & CP 5122 & CB 45-3 & NA 5679 & CP 5122 \\
\hline Cana Planta 1980 & 153,8 & 143,8 & 138,9 & 66,5 & 71,6 & 62,7 \\
\hline 1a SOCA & 1981 & 100,2 & 109,8 & 99,6 & 71,6 & 70,8 & 69,4 \\
\hline 2a SOCA & 1982 & 113,8 & 103,5 & 113,1 & 59,0 & 60,2 & 52,6 \\
\hline 3a SOCA & 1983 & 93,4 & 93,1 & 99,0 & 34,1 & 36,7 & 47,5 \\
\hline 4a SOCA & 1984 & 93,4 & 97,9 & 93,8 & 50,8 & 43,7 & 64,8 \\
\hline 5a SOCA & 1985 & 96,1 & 84,6 & 107,0 & 49,9 & 47,7 & 44,2 \\
\hline 6a SOCA & 1986 & 77,7 & 68,3 & 66,3 & 23,1 & 21,4 & 23,2 \\
\hline 7a SOCA & 1987 & 92,2 & 79,1 & 36,3 & 53,1 & 43,0 & 52,8 \\
\hline 8a SOCA & 1988 & 94,1 & 81,1 & 92,7 & 51,2 & 44,1 & 47,2 \\
\hline 9a SOCA & 1989 & 94,5 & 71,4 & 82,2 & 29,1 & 18,4 & 33,4 \\
\hline 10a SOCA & 1990 & 86,4 & 83,4 & 71,4 & 39,2 & 22,1 & 34,6 \\
\hline MÉDIA & & $\mathbf{9 8 , 7}$ & $\mathbf{9 2 , 3}$ & $\mathbf{9 5 , 5}$ & $\mathbf{4 7 , 9}$ & $\mathbf{4 4 , 1}$ & $\mathbf{4 8 , 4}$ \\
\hline
\end{tabular}

Fonte: PLANALSUCAR

As principais características desejáveis nas variedades de cana, quando irrigada são: elevada produtividade de colmo e alto teor de sacarose; precocidade e longevidade das socas; baixo índice de tombamento; boa resistência a pragas e doenças e facilidade para colheita mecanizada. 


\subsection{Tipos de irrigação para a cana-de-açúcar}

Os métodos e sistemas de irrigação utilizados em cana de açúcar são: Superfície (Sulco), Aspersão (Convencional, Autopropelido, Montagem direta, Pivô central, Linha lateral móvel) e Subterrânea (Elevação do lençol freático e Gotejamento subterrâneo).

Ainda são muito utilizados os canhões em montagem direta ou carretel enrolador, especialmente quando se faz irrigação com vinhaça. Todavia estes equipamentos, apesar de representarem um menor investimento em relação aos outros sistemas de irrigação, são os que apresentam o maior custo de operação por necessitarem de alta pressão para o seu funcionamento.

Outros sistemas automatizados que operam com pressões menores são os pivôs centrais, deslocamento linear e o gotejamento, e todos eles podem ser utilizados na irrigação da cana-de-açúcar. É importante frisar que não existe um melhor sistema de irrigação, e, sim, aquele que melhor se adapte às condições de clima, solo (textura e topografia) e cultura da propriedade que se quer irrigar.

Neste caso, um engenheiro agrônomo ou agrícola é capaz de analisar estes fatores e propor o sistema mais adequado para a propriedade tanto do ponto de vista técnico como do financeiro.

\subsection{Custos da irrigação da cana-de-açúcar}

O alto custo de implantação dos sistemas de irrigação, aliado à relação direta existente entre o custo de operação da irrigação e a quantidade de água a ser aplicada, conduz cada vez mais à necessidade de se aperfeiçoar tanto o uso da água com um bom manejo da irrigação, quanto dos demais insumos de produção. Dos fatores complementares da produção agrícola, a água e a adubação são aqueles que limitam os rendimentos com maior intensidade, considerando um bom material genético e um bom controle de pragas e doenças. Deste modo, as aplicações racionais da irrigação e da adubação são fundamentais para o aumento da produtividade e do retorno econômico na agricultura irrigada. Estas aplicações racionais da irrigação podem ser conseguidas quando se conhecem os efeitos da lâmina total aplicada (precipitação + irrigação) na produtividade das culturas, nas diferentes regiões do País.

Os custos dos sistemas de irrigação variam com os métodos de irrigação utilizados, com as culturas irrigadas, com a topografia e tipo de solo e com a região. 
Dados levantados por Soares et al. (2003) sobre custos de implantação de sistemas de irrigação, produtividade e eficiência do uso de água para cana-de-açúcar na Usina Agrovale, Juazeiro(BA), com área cultivada de aproximadamente 15.000 ha, podem ser assim resumidos na tabela 5 .

TABELA 5: Custos de implantação de sistemas de irrigação

\begin{tabular}{|c|c|c|c|c|c|c|}
\hline \multicolumn{2}{|c|}{} & $\begin{array}{c}\text { Sulco } \\
\text { com } \\
\text { canal }\end{array}$ & $\begin{array}{c}\text { Sulco } \\
\text { com } \\
\text { tubo } \\
\text { janelado }\end{array}$ & $\begin{array}{c}\text { Pivô } \\
\text { central }\end{array}$ & $\begin{array}{c}\text { Sistema } \\
\text { Linear }\end{array}$ & $\begin{array}{c}\text { Gotejamen } \\
\text { to }\end{array}$ \\
\hline $\begin{array}{c}\text { Custo de } \\
\text { Implantação }\end{array}$ & $\begin{array}{c}(\mathrm{R} \$ / \mathrm{ha} \\
)^{*}\end{array}$ & 450,00 & $1.513,00$ & $5.870,00$ & $6.562,00$ & $6.243,00$ \\
\hline $\begin{array}{c}\text { Produtividad } \\
\text { e }\end{array}$ & $(\mathrm{t} / \mathrm{ha})$ & 98 & 98 & 130 & - & 116 \\
\hline $\begin{array}{c}\text { Eficiência de } \\
\text { uso de água }\end{array}$ & $\begin{array}{c}\mathrm{Kg} / \mathrm{m}^{3} \\
\text { * US\$ = R\$2,90 }\end{array}$ & 4,9 & 4,9 & 7,15 & - & 7,13 \\
\hline
\end{tabular}

Fonte: Soares et al (2003)

Dados citados por Santos (2005) sobre custos anuais (custos fixos + custos operacionais) da irrigação por aspersão com montagem direta na cultura da cana-deaçúcar, em São Paulo, para uma lâmina de 265 mm/ano foi de R $\$ 605,00$ e, em Alagoas, para uma lâmina de 120 a $180 \mathrm{~mm} /$ ano (2 e 3 irrigações de $60 \mathrm{~mm}$ cada) foi de $\mathrm{R} \$ 870,00 /$ ha, sendo a cotação do dólar, na época, era US $\$=\mathrm{R} \$ 2,30$.

\section{CONSIDERAÇÕES FINAIS}

A prática da irrigação deve ser entendida não somente como um seguro contra secas ou veranicos, mas como uma tecnologia que pode dar condições para que a cultura expresse todo o seu potencial produtivo. Além disso, se bem utilizada, a irrigação é um instrumento muito eficaz na aumento da rentabilidade dos empreendimentos, permitindo a racionalização dos insumos, por meio de fertirrigação. No entanto, para que o processo seja eficiente, é imperativo que o sistema de irrigação tenha uma alta uniformidade de aplicação da água, isto conseguido com bons projetos, feitos a partir de matérias de qualidade, obtidos em empresas idôneas e com cálculos hidráulicos precisos.

A finalidade básica da irrigação é proporcionar água às culturas de maneira a atender as exigências hídricas durante todo seu ciclo, possibilitando altas produtividades e produtos de boa qualidade; sendo que a quantidade de água necessária às culturas é 
função da espécie cultivada, do local de cultivo, do estágio de desenvolvimento da cultura, do tipo de solo e da época de plantio.

Os dois primeiros estágios são os mais críticos ao déficit hídrico. O terceiro estágio (desenvolvimento) responde à lâmina aplicada, mas o déficit hídrico não causa tantos prejuízos à produtividade quanto aos dois primeiros. O quarto estágio (maturação) responde positivamente ao déficit hídrico, entretanto o consumo diário de água é maior no terceiro estágio do que nos dois primeiros. Isso ocorre em função do maior índice de área foliar no terceiro estágio.

Além da relevância do cultivo irrigado da cana-de-açúcar no aumento da produtividade, da produção e do número de cortes por plantio (vida útil do canavial) e, como conseqüência, no aumento do lucro do produtor, existem os benefícios socioeconômicos indiretos, tais como o aumento do número de empregos na região, os quais somente serão duradouros se os cultivos irrigados tiverem sustentabilidade econômica, social e ambiental.

Os métodos e sistemas de irrigação mais utilizados em cana de açúcar são: Superfície (Sulco), Aspersão (Convencional, Autopropelido, Montagem direta, Pivô central, Linha lateral móvel) e Subterrânea (Elevação do lençol freático e Gotejamento subterrâneo).

Dos fatores complementares da produção agrícola, a água e a adubação são aqueles que limitam os rendimentos com maior intensidade, considerando um bom material genético e um bom controle de pragas e doenças. Deste modo, as aplicações racionais da irrigação e da adubação são fundamentais para o aumento da produtividade e do retorno econômico na agricultura irrigada.

\section{REFERÊNCIAS}

ASSIS, P. C. de O. et al. Resposta dos parâmetros tecnológicos da cana-de-açúcar a diferentes lâminas de irrigação e adubação. Revista de Biologia e Ciência da Terra, Paraíba, v. 4, n. 2, 2004.

Atuação da Irriger na Cana Irrigada, Irriger, set. 2007. Disponível em http://www.irriger.com.br/noticias.php?escolha=13. Acesso em: 30 abr. 2008.

BERNARDO, S. Manual de irrigação. 7.ed. Viçosa: UFV, 2005. p.611.

BERNARDO, S; Soares, A. A; MANTOVANI, E. C. Manual de irrigação. 8.ed. Viçosa: UFV, 2006. p.361-570. 
BERNARDO, S. Manejo da irrigação na cana- de- açúcar. Disponível em http://www.agronegocio.goias.gov.br/docs/portal/seminarioIII.pdf. Acesso em: 30 abr. 2008.

DOORENBOS, J; KASSAN, A. K. Efeito da água no rendimento das culturas. Campina Verde: Universidade Federal da Paraíba, 1994. p. 220-226.

IRRIGAÇÃO aumenta produtividade e qualidade da cana, Valley, maio 2006.

Disponível em http://www.pivotvalley.com.br/?noticias,,166. Acesso em: 30 abr. 2008.

NETO, J. D. et al. Resposta da cana-de-açúcar, primeira soca, a níveis de irrigação e adubação de cobertura. Rev. Bras. Eng. Agr. e Ambient., Campina Grande-PB, v.10, n.2, p.283-288, 2006.

SANTOS, M.A.L dos, Irrigação suplementar da cana-de-açúcar (Saccharum spp): Um modelo de análise de decisão para o estado de Alagoas. P.100, 2005. Tese (Doutorado em Agronomia - Irrigação e Drenagem). Escola Superior de Agricultura "Luiz de Queiroz". Universidade de São Paulo. Piracicaba.

SILVA, S. A. da; HERNANDEZ, F. B.T. Irrigação em cana-de-açúcar, abr. 2008. Disponível em http://www.agr.feis.unesp.br/irrigacao_em_cana_abril08.php. Acesso em: 30 abr. 2008.

SOARES, J. M. et al. Agrovale,uma experiência de 25 anos em irrigação da cana- deaçucar na região do Submédio São Francisco. Revista ITÉM, n. 60, 2003, P.55- 62.

SOUZA, E. F; BERNARDO, S; CARVALHO, J. A. Função de produção da cana- deaçúcar em relação à água para três cultivares, em campos dos Goytacazes, RJ. Eng. Agríc., Jaboticabal-SP, v. 19, n.1, p.28- 42, 1999.

VEIGA, C. F. M; VIEIRA, J. R; MORGADO, I.V. Diagnóstico da cadeia produtiva da cana- de- açúcar do estado do Rio de Janeiro: relatório de Pesquisa, Rio de Janeiro: FAERJ: SEBRAE/RJ, p.107, 2006. 
